\title{
Myxoid Leiomyoma
}

National Cancer Institute

\section{Source}

National Cancer Institute. Myxoid Leiomyoma. NCI Thesaurus. Code C67563.

A leiomyoma characterized by the presence of abundant myxoid matrix. 